Article

\title{
Increased Flavonol Levels in Tobacco Expressing AcFLS Affect Flower Color and Root Growth
}

\author{
Sangkyu Park, Da-Hye Kim, Ju-Hee Yang, Jong-Yeol Lee and Sun-Hyung Lim *
}

National Institute of Agricultural Sciences, Rural Development Administration, JeonJu 54874, Korea; psk2779@korea.kr (S.P.); kimdh143@jbnu.ac.kr (D.-H.K.); didwngml77@naver.com (J.-H.Y.); jy0820@korea.kr (J.-Y.L.)

* Correspondence: limsh2@korea.kr; Tel.: +82-63-238-4615

Received: 19 December 2019; Accepted: 2 February 2020; Published: 4 February 2020

\begin{abstract}
The onion (Allium cepa L.) flavonol synthase (AcFLS-HRB) gene, encoding an enzyme responsible for flavonol biosynthesis in yellow onion, was recently identified and enzymatically characterized. Here, we performed an in vivo feeding assay involving bacterial expression of AcFLS-HRB and observed that it exhibited both flavanone 3-hydroxylase (F3H) and FLS activity. Transgenic tobacco (Nicotiana tabacum) expressing AcFLS-HRB produced lighter-pink flowers compared to wild-type plants. In transgenic petals, AcFLS-HRB was highly expressed at the mRNA and protein levels, and most AcFLS-HRB protein accumulated in the insoluble microsomal fractions. High-performance liquid chromatography (HPLC) analysis showed that flavonol levels increased but anthocyanin levels decreased in transgenic petals, indicating that AcFLS-HRB is a functional gene in planta. Gene expression analysis showed the reduced transcript levels of general phenylpropanoid biosynthetic genes and flavonoid biosynthetic genes in AcFLS-HRB overexpressed tobacco petals. Additionally, transgenic tobacco plants at the seedling stages showed increased primary root and root hair length and enhanced quercetin signals in roots. Exogenous supplementation with quercetin 3-O-rutinoside (rutin) led to the same phenotypic changes in root growth, suggesting that rutin is the causal compound that promotes root growth in tobacco. Therefore, augmenting flavonol levels affects both flower color and root growth in tobacco.
\end{abstract}

Keywords: Allium cepa; anthocyanin; flavonoid; flavonol; flavonol synthase; flower color; root growth

\section{Introduction}

Flavonoids, one of the largest groups of plant secondary metabolites, are involved in plant growth, development, reproduction, and responses to biotic and abiotic stress [1]. More than 10,000 different flavonoid compounds have been described [2,3], which are categorized into six subclasses based on their structural properties: flavanones, flavones, isoflavones, flavonols, proanthocyanidins, and anthocyanins [4]. Flavonols are the most abundant flavonoid compounds in plants and have received much attention due to their various physiological roles, including the regulation of auxin transport [5], symbiont attraction [6], male fertility [7,8], protection against UV-B irradiation [9], and the recruitment of pollinators [10].

The flavonoid biosynthesis pathway was thoroughly investigated, and most of the enzymes involved were identified in several plant species [10-13]. Phenylalanine ammonia lyase (PAL) catalyzes the deamination of phenylalanine to yield cinnamic acid, which is the first committed step in phenylpropanoid biosynthesis. The flavonoid biosynthesis pathway is initiated by the activity of chalcone synthase (CHS), an important regulatory point that affects the metabolic flux of flavonoids, which condenses one molecule of 4-coumaroyl CoA generated through the phenylpropanoid pathway with three molecules of malonyl-CoA, resulting in chalcone formation. Chalcone is further 
converted to the (2S)-flavanone naringenin by chalcone isomerase (CHI). From this central intermediate naringenin, diverse classes of flavonoids are generated through several side branches. Flavanone 3-hydroxylase ( $\mathrm{F} 3 \mathrm{H})$ catalyzes the conversion of (2S)-flavanones (e.g., naringenin and eriodictyol) to dihydroflavonols (e.g., dihydrokaempferol and dihydroquercetin). Flavonol synthase (FLS) and dihydroflavonol 4-reductase (DFR) compete for the dihydroflavanols to produce flavonol aglycones (e.g., kaempferol and quercetin) and leucoanthocyanidins, respectively. Once the flavonol aglycones are biosynthesized, the glycosylation of flavonols is catalyzed by glucosyltransferase (GT) and rhamnosyltransferase (RT), which are active in the cytosol and render hydrophobic flavonols more soluble and less toxic to facilitate their transport and storage [14-19]. Leucoanthocyanidins are converted to anthocyanidins (e.g., pelargonidin and cyanidin) by anthocyanidin synthase (ANS) and further glycosylated by UDP-glucose:flavonoid 3-O-glucosyltransferase (UFGT), resulting in anthocyanins. Flavonoid $3^{\prime}$-hydroxylase $\left(\mathrm{F}^{\prime} \mathrm{H}\right)$ catalyzes $3^{\prime}$-hydroxylation of the flavonoid B-ring, which imparts diversity to flavonoid molecules (Figure 1).

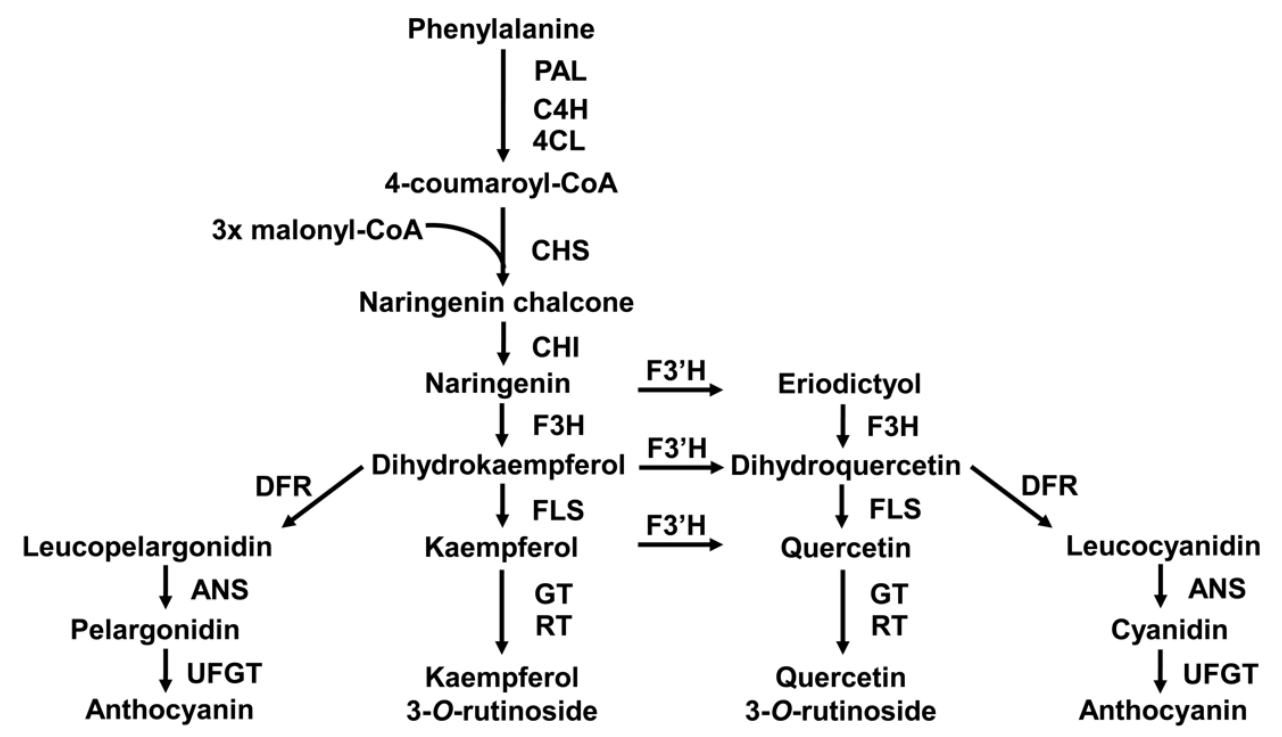

Figure 1. Flavonoid biosynthesis in plants. PAL, phenylalanine ammonia lyase; $\mathrm{C} 4 \mathrm{H}$, cinnamic acid 4-hydroxylase; 4CL, 4-coumaric acid:CoA ligase; CHS, chalcone synthase; CHI, chalcone isomerase; F3' $\mathrm{H}$, flavonoid 3'-hydroxylase; F3H, flavanone 3-hydroxylase; FLS, flavonol synthase; DFR, dihydroflavonol 4-reductase; ANS, anthocyanidin synthase; GT, glucosyltransferases; RT, rhamnosyltransferase; UFGT, UDP-glucose:flavonoid-3-O-glucosyltransferase.

The competition between FLS and DFR for dihydroflavonols creates a critical branch point separating the flavonol and anthocyanin biosynthetic pathways. Several studies used antisense down-regulation or the overexpression of FLS and DFR to characterize these genes and their roles in regulating flower color [20-22]. Antisense FLS in the flowers of Eustoma grandiflorum Grise, Petunia hybrida, and Mimulus lewisii caused a decrease in flavonol contents and an increase in anthocyanin levels, resulting in flowers with enhanced coloration. Conversely, antisense DFR in tobacco led to an increase in flavonol contents and a decrease in anthocyanin contents, resulting in white flowers [23]. When FLS genes from Rosa rugosa, Prunus persica, or Petunia hybrida were expressed in tobacco, the resulting flowers contained increased levels of flavonol and decreased levels of anthocyanin, while transgenic tobacco expressing DFR genes from Rosa rugosa or Petunia hybrida showed the opposite phenotypes [24]. These inverse correlations between flavonol and anthocyanin production are commonly observed. Several transcription factor families, including R2R3-MYB, basic helix-loop-helix (bHLH), WD40, are involved in the transcriptional control of phenylpropanoid and flavonoid biosynthesis genes [25-28]. Among these, certain R2R3-MYB and bHLH transcription factors are involved in regulating FLS or DFR expression. The heterologous expression of the Arabidopsis 
thaliana gene MYB12 in tobacco enhanced the expression of FLS and resulted in the accumulation of flavonols, demonstrating that AtMYB12 positively regulates FLS [29]. In Zea mays, ZmFLS1 is directly up-regulated by the collaborative activity of the R2R3-MYB transcription factor C1 and bHLH transcription factor $\mathrm{R}$ [30], while in Malus $\times$ domestica, MYB10 positively regulates DFR expression and therefore anthocyanin accumulation [31]. However, the mechanism explaining the inverse correlation between flavonol and anthocyanin biosynthesis has not yet been clarified.

Flavonols are important regulators not only of flower color, but also of root growth and development. Flavonols inhibit polar auxin transport (PAT), a process mediated by several auxin transporters [32]. The intercellular migration of auxin is closely related to the asymmetric subcellular localization of the major auxin efflux carriers PINs, which can be altered by phosphorylation of PINs by protein kinase PINOID [33]. Flavonols inhibit PINOID activity, thus reducing the phosphorylation level of PIN2, leading to a change in PIN2 localization. Therefore, flavonols play important roles in determining whether auxin flow is directed towards the shoot or root [33]. The reactive oxygen species (ROS)-scavenging activity of flavonols highlights their importance in root growth and development. Auxin triggers the production of $\mathrm{O}_{2}{ }^{-}$, which promotes cell division in the meristematic zone, whereas cytokinin and $\mathrm{H}_{2} \mathrm{O}_{2}$ cooperatively arrest cell division and initiate differentiation in the elongation and differentiation zones $[34,35]$. This antagonistic relationship between auxin- $\mathrm{O}_{2}{ }^{-}$and cytokinin $-\mathrm{H}_{2} \mathrm{O}_{2}$ controls the balance between cell division and differentiation in the root. Cytokinin and $\mathrm{H}_{2} \mathrm{O}_{2}$ induce flavonol biosynthesis, which inhibits root-ward PAT by disturbing PIN localization and scavenging $\mathrm{O}_{2}{ }^{-}$to reduce cell division in the meristem [35]. Therefore, in Arabidopsis, increased flavonol levels result in reduced primary root length, whereas the suppression of flavonol accumulation causes the opposite phenotype [36]. However, the tomato mutant anthocyanin reduced (are), harboring deficient $\mathrm{F} 3 \mathrm{H}$ and significantly reduced flavonol levels, has shorter primary roots than the wild-type [37]. These findings indicate that the patterns of flavonol-mediated root growth differ depending on the plant species, since root phenotypes result from the integrated signaling of PAT, ROS, and flavonol.

Both kaempferol and quercetin are active components of PAT. However, the derivatives of each compound are thought to play different roles in PAT. The accumulation of kaempferol-3-O-glucoside in the rol1-2 mutant (harboring a mutation in rhamnose synthase 1) is responsible for the positive regulation of PAT in the shoot and its negative regulation in the root [38]. The accumulation of kaempferol 3-O-rhamnoside-7-O-rhamnoside in the $u g t 78 d 2$ mutant (harboring a mutation in the flavonoid 3-O-glucosyltransferase gene) is responsible for the negative regulation of PAT in the shoot [39]. Finally, the accumulation of quercetin-3-O-rhamnoside in WRKY23 overexpression (activator of $F 3^{\prime} H$ ) plants is responsible for the negative regulation of PAT in the root [40]. The number of hydroxyl groups on the B-rings of flavonols differentially affects their ability to scavenge free radicals, and other types of modifications, such as glycosylation, methylation, and acylation, cause variations in the antioxidant capacities for different types of ROS [41]. Therefore, the specific flavonol compositions in different plant species may have different effects on regulating root growth and development.

Several FLS genes were identified from dicot and monocot plants, and their enzymatic properties and/or functionalities were characterized in planta [42-50]. Among these, AtFLS1, CitFLS, GbFLS, and OsFLS are bifunctional enzymes exhibiting both F3H and FLS activity $[42,44,46,50]$. Recently, two FLS genes (AcFLS-HRB and AcFLS-H6) were identified in two different colored onion (Allium cepa) cultivars, the yellow onion 'Hwangryongball' ('HRB') and ' $\mathrm{H} 6$ ', a double haploid line of red onion, respectively [49]. Enzymatic characterizations of the two AcFLS genes revealed that the preferred substrate of both enzymes is dihydroquercetin (DHQ) over dihydrokaempferol (DHK) and that AcFLS-HRB exhibits higher catalytic efficiency than AcFLS-H6. Here, we carried out an in vivo feeding assay via bacterial expression of AcFLS-HRB and found that AcFLS-HRB is a bifunctional enzyme with both F3H and FLS activity. We verified its functions in planta through phenotypic, molecular, and biochemical analysis of transgenic tobacco expressing AcFLS-HRB. Transgenic tobacco produced lighter-pink flowers containing higher flavonol levels and lower anthocyanin levels than the wild-type. In accordance with these phenotypes, phenylpropanoid biosynthesis genes and several flavonoid 
biosynthetic genes were down-regulated in transgenic petals. We also observed changes in root growth in the transgenic tobacco plants, with longer primary roots and root hairs than the wild-type, which was consistent with the accumulation patterns of quercetins in the roots. These findings indicate that increased quercetin levels promote root growth in tobacco.

\section{Results}

\subsection{Recombinant AcFLS-HRB Protein Exhibits both F3H and FLS Activity}

To determine whether AcFLS-HRB is a bifunctional enzyme, we expressed recombinant AcFLS-HRB protein fused with GST (glutathione S-transferase) in E. coli and measured its activity by substrate-feeding in bacterial culture medium. Equal amounts of racemic flavanone substrates (naringenin and eriodictyol) were simultaneously added to bacterial cultures expressing GST only and GST-AcFLS-HRB after isopropyl $\beta$-D-1-thiogalactopyranoside (IPTG) induction. After $3 \mathrm{~h}$ of incubation, we extracted the products and analyzed them by high-performance liquid chromatography (HPLC) (Figure 2A). SDS-PAGE confirmed that recombinant proteins were successfully expressed in the cultures (Figure 2B). HPLC analysis showed that both dihydroflavonols (DHK and DHQ) and flavonols (kaempferol and quercetin) were produced in cultures expressing GST-AcFLS-HRB, indicating that GST-AcFLS-HRB converted flavanone substrates to dihydroflavonols and further converted the dihydroflavonols to flavonols. These results indicate that GST-AcFLS-HRB exhibits F3H activity as well as FLS activity.
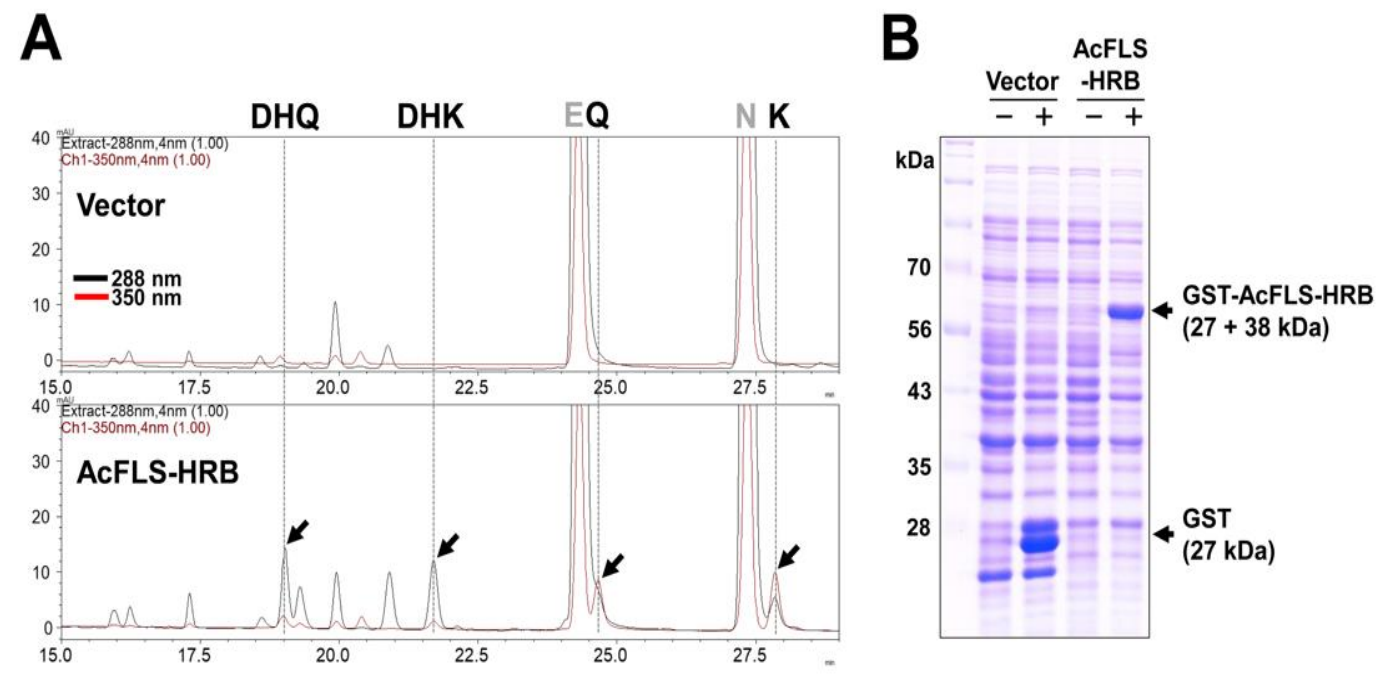

Figure 2. In vivo substrate-feeding assay of AcLFS-HRB enzyme activity. (A). E. coli strain BL21 cells harboring recombinant GST (Vector) and expressing GST-AcFLS-HRB were simultaneously fed with flavanones (naringenin $[\mathrm{N}]$ and eriodictyol $[\mathrm{E}]$ ), and the resulting dihydroflavonols (DHK and DHQ) and flavonols (kaempferol [K] and quercetin [Q]) were analyzed by HPLC. Flavanones and dihydroflavonols were detected at $288 \mathrm{~nm}$, and flavonols were detected at $350 \mathrm{~nm}$. Arrows indicate products from the bacterial culture expressing AcFLS-HRB. (B). Recombinant protein expression induced by IPTG (-, noninduced; +, induced) was confirmed by SDS-PAGE.

\subsection{Transgenic Tobacco Expressing AcFLS-HRB Has Lighter-Pink Flowers than the Wild-Type}

We obtained more than $20 \mathrm{~T}_{0}$ transgenic tobacco (Nicotiana tabacum $\mathrm{cv}$ Xanthi) lines expressing AcFLS-HRB driven by the CaMV $35 S$ promoter and their seeds were obtained from self-pollinated plants. After progressing to the $\mathrm{T}_{1}$ generation, their phenotypes were analyzed. Compared to wild-type (WT) flowers, the flowers of $T_{1}$ transgenic lines showed decreases in pinkness to various extents (Figure $3 \mathrm{~A}$ ). Based on their flower colors, the $\mathrm{T}_{1}$ lines were divided into two groups, light pink (LP) and pale pink (PP), and two representative plants were selected from each group. On the other hand, 
no phenotypic differences in growth and development between WT and the transgenic lines were observed (Figure 3B).

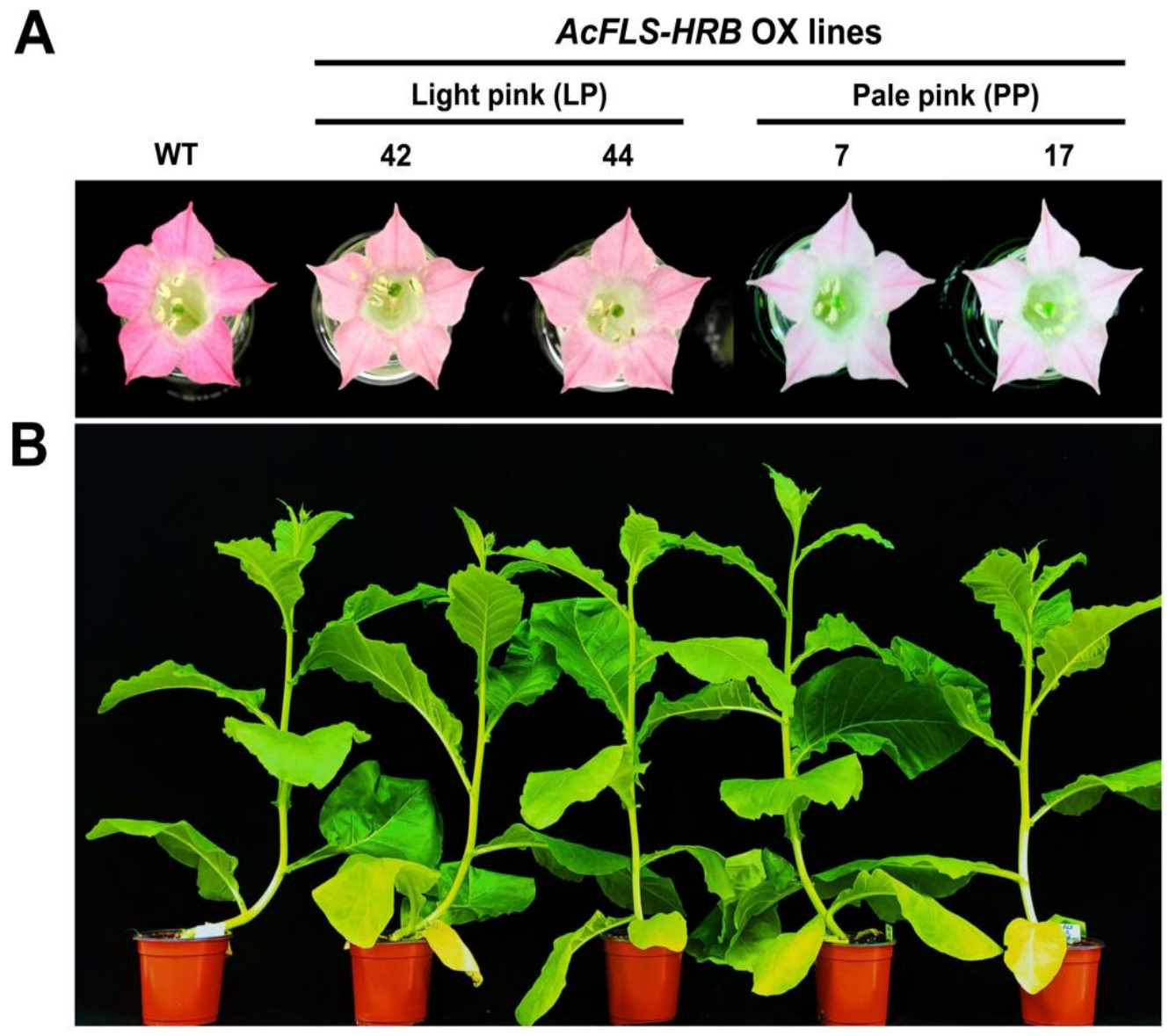

Figure 3. Phenotypes of transgenic tobacco expressing AcFLS-HRB. Phenotypes of flowers (A) and 9-week-old plants (B) expressing AcFLS-HRB. WT, wild-type; 42, 44, 7, and 17, transgenic lines with light pink/pale pink flowers.

\subsection{Expression of AcFLS-HRB in Tobacco Increases Flavonol and Decreases Anthocyanin Levels in Flowers}

Acid-hydrolyzed flavonoid aglycones were extracted from their flower petals and analyzed using HPLC, and their contents were calculated based on the areas of corresponding standards. The dihydroflavonol levels in transgenic petals were approximately $50 \%$ those of WT petals (Figure 4). The DHK levels were much more greatly reduced than the DHQ levels, with decreases of $63 \%$ to $81 \%$ and $25 \%$ to $58 \%$, respectively, compared to the WT. By contrast, the levels of flavonols, including kaempferol and quercetin, tended to increase with decreasing intensity of the pink coloration in petals, with overall changes of $5 \%$ to $28 \%$ in the LP lines and $20 \%$ to $24 \%$ in the PP lines relative to the WT. The levels of quercetin in the petals were generally higher than those of kaempferol; however, the increase in kaempferol levels in the transgenic plants (17-49\%) was more pronounced than the increase in quercetin levels (7-10\%, except for line 42$)$. The levels of cyanidin-derived anthocyanins, the major class of anthocyanins in the petals of tobacco flowers, were greatly reduced in transgenic petals relative to the WT, with the largest decreases (71-76\%) observed in the PP lines. These results indicate that the functional expression of AcFLS-HRB in tobacco caused an increase in flavonol accumulation and a decrease in anthocyanin accumulation in the transgenic petals, resulting in light pink and pale pink flowers. 

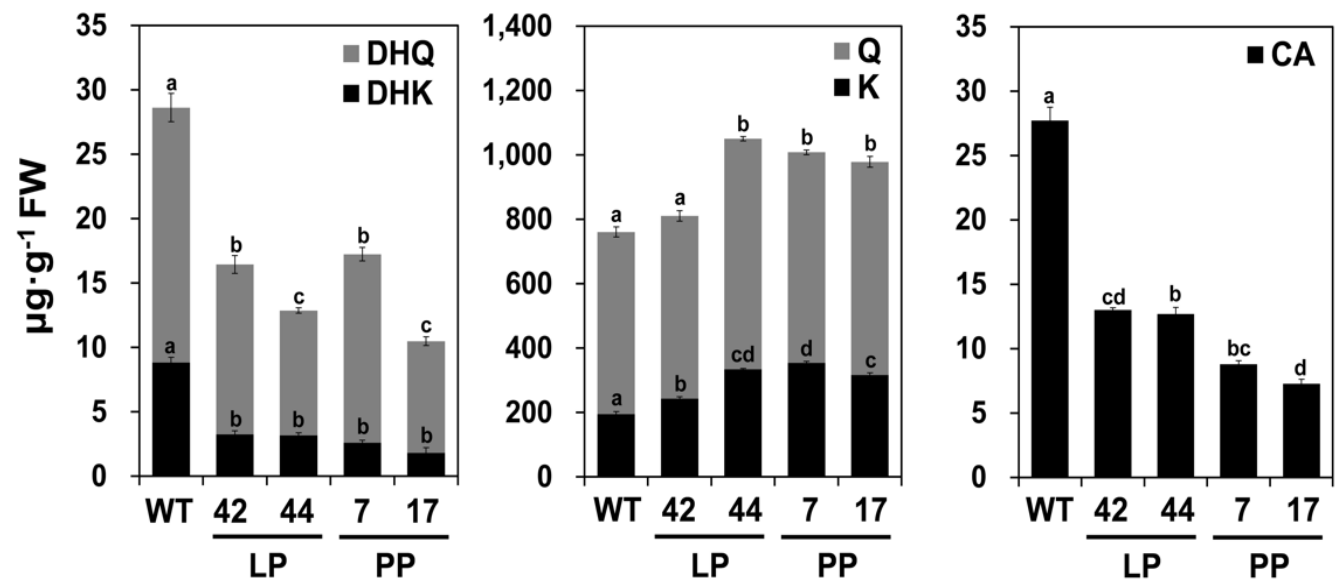

Figure 4. Flavonoid contents in the petals of transgenic tobacco flowers expressing AcFLS-HRB. A, HPLC analysis of flavonoid aglycones extracted from the petals of WT and transgenic lines (42, $44,7,17)$ via acid hydrolysis. Peaks corresponding to dihydroflavonols (DHQ and DHK), flavonols (Q, quercetin; K, kaempferol), and cyanidin (CA) were detected at $288 \mathrm{~nm}, 350 \mathrm{~nm}$, and $520 \mathrm{~nm}$, respectively. B, Flavonoid contents were measured in accordance with the area of each standard. Error bars indicate \pm SD from three replicates. Statistical significance was determined by one-way ANOVA with post-hoc Tukey's tests. Significant differences between means $(p<0.05)$ are indicated by lower-case letters ( $a, b, c$, and d) above the bars. LP, light pink transgenic lines; PP, pale pink transgenic lines.

\subsection{Anthocyanin Biosynthesis Genes Are Down-Regulated in AcFLS-HRB Transgenic Tobacco Petals}

We examined AcFLS-HRB transcript abundance and AcFLS-HRB protein levels in transgenic tobacco petals by quantitative RT-PCR (qPCR) and immunoblot analysis, respectively. AcFLS-HRB was highly expressed in transgenic petals, with higher transcript levels in the PP lines vs. the LP lines (Figure 5A). Consistently, AcFLS-HRB protein was only present in the transgenic lines, with very high levels in the PP lines (Figure 5B). Notably, most of the proteins were detected in the soluble fraction of total extracts rather than the insoluble microsomal fraction, indicating that the majority of AcFLS-HRB protein was present in a soluble form in petal cells.
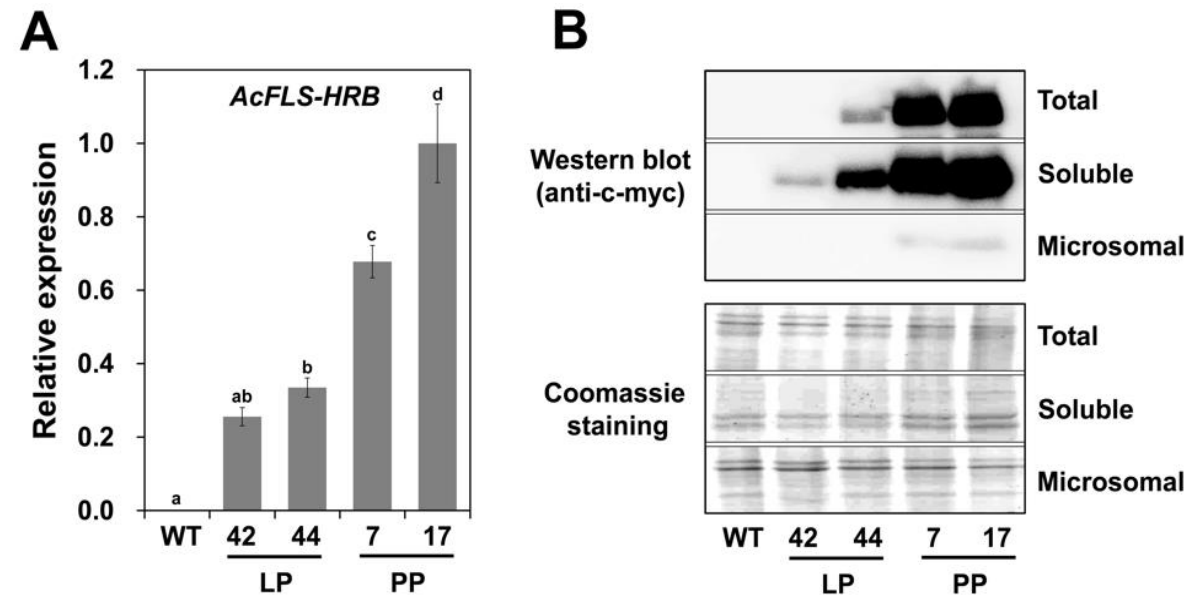

Figure 5. AcFLS-HRB expression and protein contents in WT and AcFLS-HRB-expressing transgenic tobacco petals. (A), Relative expression levels of AcFLS-HRB in WT and transgenic tobacco petals, as revealed by qPCR. Error bars indicate \pm SD from three replicates. Statistical significance was determined by one-way ANOVA with post-hoc Tukey's tests. Significant differences between means $(p<0.05)$ are indicated by lower-case letters (a, b, c, and d) above the bars. (B), Immuno blot analysis of WT and transgenic petals using anti-c-myc antibody. Coomassie staining was conducted for the loading control. LP, light pink transgenic lines; PP, pale pink transgenic lines. 
Unlike AcFLS-HRB, the flavonoid biosynthetic genes were generally down-regulated in transgenic petals (Figure 6). Genes of the phenylpropanoid biosynthesis pathway, such as NtPAL and Nt4CL, and the early biosynthetic genes (EBGs) in the flavonoid pathway, including NtCHS and NtCHI, were significantly down-regulated. In the case of the late biosynthetic genes (LBGs) involved in anthocyanin biosynthesis, such as NtDFR and NtANS, there was little to no repression in the LP lines but significant down-regulation in the PP lines, corresponding to the degree of reduction in the pigmentation of the petals. These results indicate that the transgenic expression of AcFLS-HRB could affect the metabolic flux of flavonoid biosynthesis and that the higher levels of AcFLS-HRB expression in the PP lines could accelerate the decrease in anthocyanin biosynthesis through the suppression of DFR and ANS expression in tobacco petals.

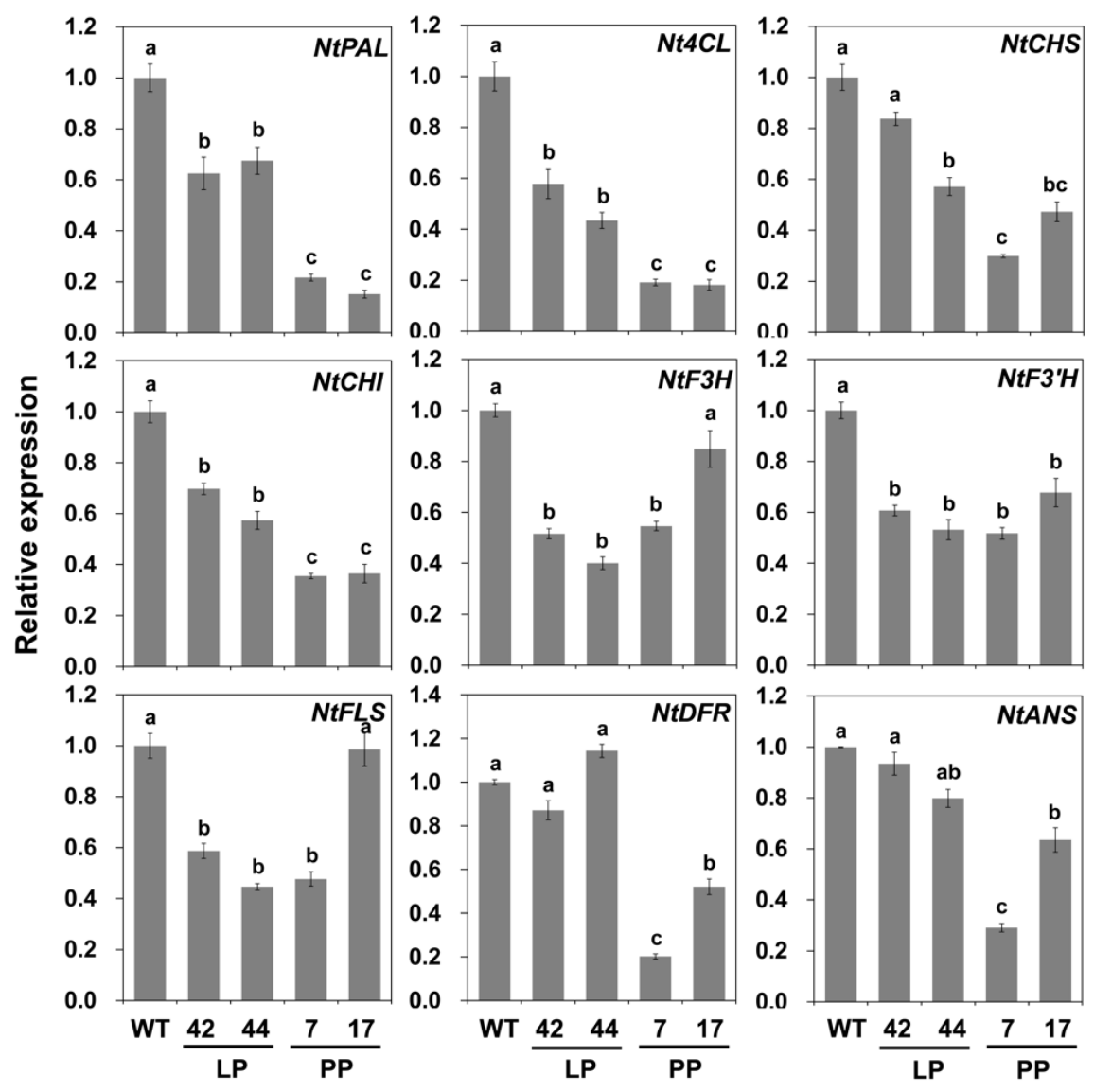

Figure 6. Expression patterns of flavonoid biosynthesis pathway genes in WT and AcFLS-HRB-expressing tobacco petals, as revealed by qPCR. LP, light pink transgenic lines; PP, pale pink transgenic lines. Error bars indicate \pm SD from three replicates. Statistical significance was determined by one-way ANOVA with post-hoc Tukey's tests. Significant differences between means $(p<0.05)$ are indicated by lower-case letters $(a, b$, and $c)$ above the bars.

\subsection{Increased Flavonol Levels in Tobacco Expressing AcFLS-HRB Promote Primary Root and Root} Hair Growth

To investigate whether the increased flavonol levels in AcFLS-HRB-expressing transgenic tobacco affect seedling growth, we examined $\mathrm{T}_{3}$ transgenic seedlings grown on vertical plates. The primary roots and root hairs were longer in the transgenic plants than in the wild-type (Figure 7A,B). To confirm that these phenotypes were directly linked to altered flavonol contents, we performed in situ flavonoid staining of transgenic roots with diphenylboric acid 2-aminoethyl ester (DPBA), a fluorescent dye that specifically interacts with flavonols. Both wild-type and transgenic tobacco roots showed the specific fluorescence of the quercetin-DPBA complex (Q-DPBA), but fluorescence of the kaempferol-DPBA 
complex was not shown, indicating that the flavonol that mainly accumulates in the roots of tobacco seedlings is quercetin rather than kaempferol. The intensity of Q-DPBA fluorescence was stronger in transgenic vs. wild-type roots. These findings suggest that the increased quercetin levels in tobacco roots stimulate primary root and root hair growth.
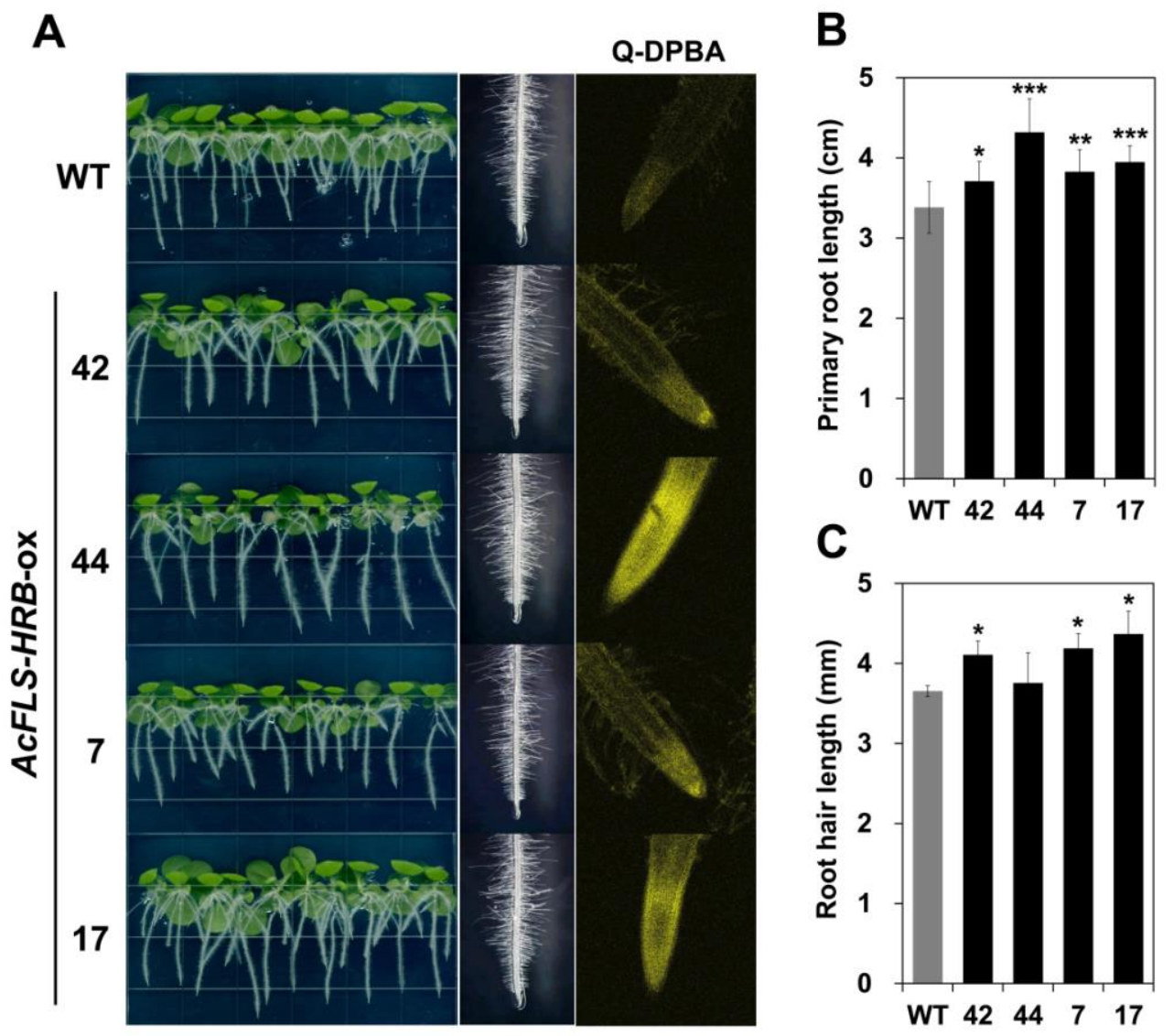

Figure 7. Changes in the root phenotypes of AcFLS-HRB-expressing tobacco seedlings. (A). Phenotypes of 16-day-old wild-type and transgenic $\left(\mathrm{T}_{3}\right)$ seedlings grown vertically on Murashige and Skoog (MS) medium (without sucrose) (left column). The root hair (middle column) and the DPBA staining of flavonols in the roots (right column) were observed by microscopic examination. (B), Average primary root length of 30 seedlings. (C), Average root hair length of at least eight primary roots. Data are expressed as mean \pm SD, as determined from the replicates. Significant differences were determined by Student's $t$-test. Asterisks indicate that the value is significantly different from that of the WT $\left({ }^{*} p<0.05\right.$, ** $\left.p<0.01,{ }^{* * *} p<0.001\right)$.

\subsection{Exogenous Rutin Treatment Enhances Primary Root and Root Hair Growth in Wild-Type Tobacco Seedlings}

DPBA staining revealed only quercetin signals in the roots of tobacco seedlings. The corresponding compound was regarded as rutin, since kaempferol 3-O-rutinoside and quercetin 3-O-rutinoside (rutin) are the major flavonols that accumulate in tobacco [50]. Therefore, we grew wild-type seedlings vertically on Murashige and Skoog (MS) medium containing 10 or $50 \mu \mathrm{M}$ rutin to verify the root growth-promoting effects of this compound. Seedlings grown on $10 \mu \mathrm{M}$ rutin (R10) showed no significant differences in root growth compared to those grown under mock treatment, whereas treatment with $50 \mu \mathrm{M}$ rutin (R50) significantly increased primary root and root hair length (Figure 8A). Primary root and root hair length in R50 increased approximately $12.6 \%$ and $93.4 \%$, respectively, compared to mock treatment (Figure 8B,C). These results suggest that rutin is an important factor that positively affects root growth, particularly root hair growth, in tobacco seedlings. 

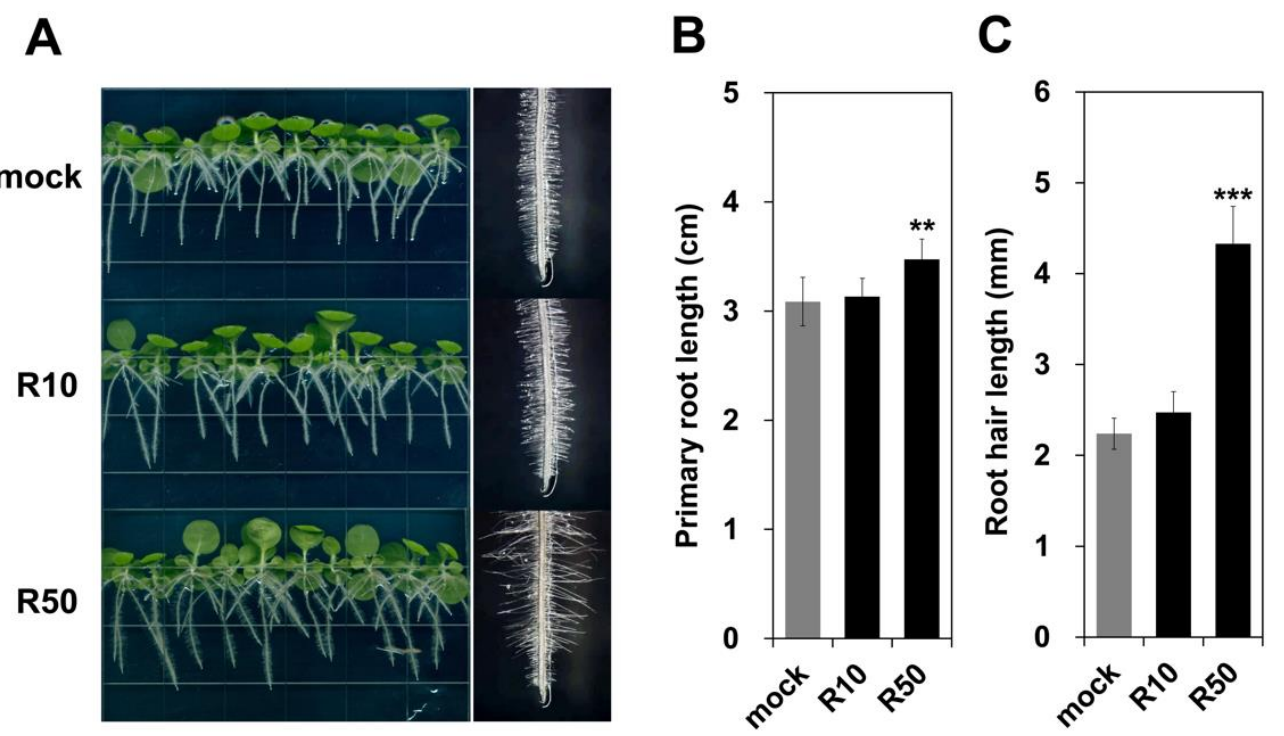

Figure 8. Root growth-promoting effects of rutin on tobacco seedlings. (A). 16-day-old wild-type seedlings grown vertically on MS medium (without sucrose) containing $10 \mu \mathrm{M}$ (R10), $50 \mu \mathrm{M}$ (R50) rutin, or DMSO (mock) were compared (left column). The root hair was observed by microscopic examination (right column). (B), Average primary root length of 30 seedlings. (C), Average root hair length of at least eight primary roots. Data are expressed as mean $\pm \mathrm{SD}$, as determined from the replicates. Significant differences were determined by Student's $t$-test. Asterisks indicate that the value is significantly different from that of mock treatment $\left({ }^{* *} p<0.01{ }^{* * *} p<0.001\right)$.

\section{Discussion}

Here, we investigated whether AcFLS-HRB is a bifunctional enzyme with both F3H and FLS activity. An in vivo substrate-feeding assay showed that flavanones could be converted to dihydroflavonols via the activity of AcFLS-HRB (Figure 2), indicating that AcFLS-HRB exhibits F3H as well as FLS activity. Among the FLSs that were enzymatically characterized in various plant species, most FLSs (OsFLS, AtFLS, CitFLS, GbFLSn, and AcFLS) are bifunctional enzymes, except for ZmFLS1 [30], suggesting that FLSs are able to substitute for the role of $\mathrm{F} 3 \mathrm{H}$ in flavonoid biosynthesis in many plant species. Indeed, flavonols and anthocyanins are produced in the $t t 6$ ( $F 3 H$ deficient) mutant, but at much lower levels than in the wild-type [51,52]. Interestingly, unlike the wild-type, $t+6$ seed coats are yellow/green at harvest but turn pale brown over time [51]. Thus, it appears that the F3H activity of FLS can augment or substitute for the function of authentic F3H enzyme, but dihydroflavonol biosynthesis by FLS is controlled in a manner different from that of F3H.

We successfully expressed the monocotyledonous AcFLS-HRB gene in dicotyledonous tobacco, which increased flavonol levels and decreased anthocyanin levels in tobacco flowers (Figures 3 and 4). This confirmed that AcFLS-HRB is a functional FLS gene in planta. ZmFLS1 and OsFLS, other monocotyledonous $F L S$ genes that were functionally characterized in planta, successfully produced flavonol in Arabidopsis and tobacco, respectively [30,50]. These findings indicate that the functionality of $F L S$ is well conserved between monocot and dicot plants. In the current study, the AcFLS-HRB transgene was highly expressed in tobacco petals; however, the total flavonol levels in the petals increased by only $5 \%$ to $28 \%$ compared to WT petals. These results appear to be due, in part, to the failure of AcFLS-HRB to interact with the flavonoid biosynthetic enzymes in tobacco. To optimize the catalytic efficiency of enzymes and co-ordinate metabolic crosstalk, sequential enzymes interact with each other to form supramolecular complexes called metabolons [53]. There is mounting evidence that flavonoid biosynthesis enzymes are able to form a metabolon, with the membrane-bound P450 enzyme F3' $\mathrm{H}$ functioning as a scaffold to bind to soluble enzymes during metabolon formation $[53,54]$. In the current study, most of the AcFLS-HRB protein was detected in the soluble fraction, with 
trace levels detected in the insoluble microsomal fraction (Figure 5B), suggesting that the number of metabolons may be insufficient to accommodate a large number of AcFLS-HRB, which may limit the metabolic capacity for flavonoid biosynthesis. Alternatively, the interaction between AcFLS-HRB and the endogenous tobacco enzymes may not be efficient due to a lack of compatibility. For these reasons, the flavonols do not appear to accumulate above a certain threshold, even in plants overexpressing FLS. Similarly, an Arabidopsis fls1 mutant complemented by ZmFLS1 accumulated flavonols at levels slightly lower than those of wild-type Arabidopsis [30]. Likewise, the transgenic expression of FLS genes isolated from rose, peach, or petunia in tobacco resulted in a 35\% increase in flavonol levels, on average [24]. However, another study showed relatively high levels of flavonol accumulation: the expression of Brassica napus FLS (BnFLS) in Arabidopsis resulted in an $85 \%$ increase in flavonol levels relative to the WT [55]. Considering that Brassica napus and Arabidopsis both belong to the Brassicaceae family, the relatively high levels of flavonol in the transgenic plants may be due to high compatibility between BnFLS and the flavonoid biosynthetic enzymes in Arabidopsis.

Our expression analysis showed that genes in the early and late steps of the flavonoid biosynthesis pathway were suppressed in transgenic petals (Figure 6). In the case of FLS suppression, a decrease in flavonols and an increase in anthocyanin levels typically occur in flower petals [20-22], but the expression of the other flavonoid biosynthetic genes are not affected [22], suggesting that the lack or reduced levels of flavonols do not affect the regulation of the flavonoid biosynthesis genes, and the metabolic flux simply flows to DFR in the absence of FLS. On the other hand, excessive flavonol levels due to FLS overexpression, as in our case, may cause the down-regulation of EBGs and LBGs in flower petals, indicating that flavonols can be causal compounds in the negative regulation of flavonoid biosynthesis. The branch point separating the flavonol and anthocyanin biosynthesis pathways is an attractive target for the molecular breeding of flower color. To obtain more intense flower color, suppression of $F L S$ and overexpression of DFR were applied simultaneously [21,56]. However, for a stronger effect, it is necessary to increase the overall metabolic flux in this pathway. For this, it could be effective to use appropriate transcription factors. In addition, if a flower-specific promoter is used, the desired plant could be successfully obtained without affecting plant growth [57]. However, when flavonol levels are excessively reduced by FLS suppression, seed set could be arrested, because flavonols are involved in auxin transport [58]. Thus, this aspect should be taken into account when designing strategies for obtaining enhanced flower color.

In addition to changes in flower color, we observed increased root growth in AcFLS-HRB-overexpressing tobacco, suggesting that the increased flavonol levels in tobacco roots promote root growth. DPBA staining revealed only quercetin signals in transgenic roots, which were likely derived from rutin, since the major flavonols in tobacco are kaempferol 3-O-rutinoside and rutin [50]. Thus, we treated wild-type tobacco plants with rutin and verified its positive effects on root growth (Figure 8). The rutin levels in tobacco increased in response to $\mathrm{NtCHS}$ overexpression and decreased by NtCHS RNAi [59]. However, changes in primary root length were not observed in the transgenic plants compared to wild-type. The enhanced rutin levels increased salt tolerance in $\mathrm{NtCHS}$-overexpressing tobacco plants, thus alleviating the decrease in root length caused by $\mathrm{NaCl}$ treatment. Plants treated with rutin plus $\mathrm{NaCl}$ had longer primary roots than plants treated with $\mathrm{NaCl}$ alone. Similarly, our results indicate that rutin promotes root growth in tobacco (Figure 8). However, flavonol accumulation or quercetin aglycone treatment suppresses root growth in Arabidopsis [36,60,61], pointing to differences in the regulation of flavonol-mediated root growth in tobacco vs. Arabidopsis. Interestingly, we detected significant increases in root hair length in transgenic tobacco and in rutin-treated wild-type plants, but the number of root hairs was not altered in both cases. The tomato are mutant, which contains trace level of flavonols but accumulates high levels of $\mathrm{H}_{2} \mathrm{O}_{2}$ in the root maturation zone, has more root hairs than the wild-type, but its root hair length is not altered [37], implying that due to the lack of flavonols, $\mathrm{H}_{2} \mathrm{O}_{2}$ scavenging does not occur, and thus root hair differentiation is highly activated. Therefore, perhaps the increased rutin levels in the root of AcFLS-HRB-overexpressing tobacco extensively scavenged $\mathrm{H}_{2} \mathrm{O}_{2}$ in the differentiation zone, which 
further arrested cell differentiation, resulting in the unaltered number of root hairs. Previously, it was observed that increased levels of rutin in tobacco more efficiently removed $\mathrm{H}_{2} \mathrm{O}_{2}$ than $\mathrm{O}_{2}{ }^{-}$[59], and another study showed that the inhibition of $\mathrm{O}_{2}{ }^{-}$bursts by blocking NADPH oxidase activity suppressed root hair elongation in Arabidopsis [62]. Therefore, we can hypothesize that high levels of rutin in tobacco root mainly scavenge $\mathrm{H}_{2} \mathrm{O}_{2}$ in the differentiation zone, $\mathrm{O}_{2}{ }^{-}$would antagonistically replace it, and the consequent increase in the ratio of $\mathrm{O}_{2}{ }^{-}$to $\mathrm{H}_{2} \mathrm{O}_{2}$ in this region may account for the promotion of root hair elongation.

Different flavonol species and specific derivatives of flavonols (rather than aglycones) have different effects on PAT and ROS scavenging [39,41]. Given the unique intracellular compositions of kaempferol and quercetin and their derivatives in different plant tissues and species with distinct flavonoid modification systems, the regulation of flavonol-mediated root growth cannot be generalized to other plant species. Here, we showed that bifunctional AcFLS expression in tobacco resulted in changes in flower color and promoted root growth by enhancing flavonol levels. Our findings also suggest that rutin is a regulatory compound that promotes root growth.

\section{Materials and Methods}

\subsection{Expression of Recombinant AcFLS-HRB Protein in E. coli and In Vivo Feeding Assay}

The AcFLS-HRB ORF was amplified using a set of specific primers (Table 1). The PCR products were cloned into the pGEX-4T-3 vector that had been linearized by BamHI digestion using an InFusion Advantage PCR Cloning Kit (Clontech, Mountain View, CA, USA) in-frame with the sequence encoding the N-terminal glutathione $S$-transferase (GST) tag. The resulting vector, pGEX-4T-3-AcFLS, was verified by sequencing and transformed into E. coli strain BL21 (DE3) cells (Novagen, Darmstadt, Germany). Transformed bacterial cells were cultured in $50 \mathrm{~mL}$ of LB broth, and protein expression was induced by adding $0.1 \mathrm{mM}$ isopropyl $\beta$-D-1-thiogalactopyranoside (IPTG) and incubation at $28^{\circ} \mathrm{C}$ for $2 \mathrm{~h}$. The racemic flavanone substrates naringenin and eriodictyol were simultaneously added to $2 \mathrm{~mL}$ of the induced culture to a final concentration of $100 \mu \mathrm{M}$ of each compound. After $3 \mathrm{~h}$ of incubation at $28^{\circ} \mathrm{C}, 800 \mu \mathrm{L}$ of the culture was harvested, sonicated, and extracted with 1 volume of ethyl acetate. The ethyl acetate extracts were evaporated with nitrogen gas, and the residues were dissolved in $100 \mu \mathrm{L}$ of methanol for HPLC analysis. Aliquots of bacterial cultures noninduced or induced by IPTG were subjected to SDS-PAGE to confirm the expression of recombinant GST-AcFLS-HRB protein.

Table 1. List of primers used for cloning and qPCR.

\begin{tabular}{cllc}
\hline Target & \multicolumn{1}{c}{ Forward $\left(5^{\prime} \rightarrow \mathbf{3}^{\prime}\right)$} & \multicolumn{1}{c}{ Reverse $\left(5^{\prime} \rightarrow \mathbf{3}^{\prime}\right)$} & Usage \\
\hline$A c F L S$ & AAAAAAGCAGGCTTTATGGAAGTAGAGAGA & TGAATTGGTTCCTTTCCCTGAGGAAGTTTATT & Cloning \\
$A c F L S$ & ACACTGACATGTCCAGCCTCACC & TTACCGTTGTTCTGTGTAGCACGC & qPCR \\
$N t P A L$ & ATTGAGGTCATCCGTTCTGC & ACCGTGTAACGCCTTGTTTC & qPCR \\
$N t 4 C L$ & TCATTGACGAGGATGACGAG & TGGGATGGTTGAGAAGAAGG & qPCR \\
$N t C H S$ & TTGTTCGAGCTTGTCTCTGC & AGCCCAGGAACATCTTTGAG & qPCR \\
$N t C H I$ & GTCAGGCCATTGAAAAGCTC & CTAATCGTCAATGCCCCAAC & qPCR \\
$N t F 3 H$ & CAAGGCATGTGTGGATATGG & TGTGTCGTTTCAGTCCAAGG & qPCR \\
$N t F 3^{\prime} H$ & AGGCTCAACACTTCTCGT & CATCAACTTTGGGCTTCT & qPCR \\
$N t F L S$ & TTTGGCACTTGGTGTTGTGG & ACTTGACATCATACCAATGG & qPCR \\
$N t D F R$ & AACCAACAGTCAGGGGAATG & TTGGACATCGACAGTTCCAG & qPCR \\
$N t A N S$ & TGGCGTTGAAGCTCATACTG & GGAATTAGGCACACACTTTGC & qPCR \\
$N t G A P D H$ & GGTGTCCACAGACTTCGTGG & GACTCCTCACAGCAGCACCA & qPCR \\
\hline
\end{tabular}

\subsection{Vector Construction for Tobacco Transformation}

The AcFLS gene was isolated from the 'Hwangryongball' onion cultivar (AcFLS-HRB) and introduced into the pTOP Blunt V2 vector (Enzynomics, Daejeon, Republic of Korea) as previously described [49]. We carried out PCR using the resulting vector pTOP Blunt V2:AcFLS-HRB as a template, with a sequence-specific primer set (Table 1) designed to complement either end of the pE3c entry vector linearized by DraI digestion. The PCR product was cloned into the DraI-digested $\mathrm{pE} 3 \mathrm{c}$ vector 
using an InFusion Advantage PCR Cloning Kit (Clontech), in-frame with the sequence encoding the C-terminal 6x c-myc tag. Subsequently, the coding region of AcFLS-HRB fused with the 6x c-myc tag was transferred to the destination vector $\mathrm{pK} 2 \mathrm{GW} 7$ to generate the final pK2GW7-AcFLS-HRB-myc construct using the GATEWAY ${ }^{\mathrm{TM}}$ system (Thermo Fisher Scientific, Waltham, MA, USA), according to the manufacturer's instructions [63]. The final vector also contained the CaMV $35 S$ promoter to drive the expression of the transgene and the kanamycin resistance gene for the selection of transgenic plants.

\subsection{Transformation of Tobacco Plants}

Transgenic tobacco was generated by transforming leaf discs with Agrobacterium tumefaciens GV3101 containing the pK2GW7-AcFLS-HRB-myc construct as described previously [64]. Briefly, tobacco seeds were surface sterilized with $70 \%$ ethanol followed by $25 \%$ commercial bleach and grown on solidified half-strength Murashige and Skoog (MS) medium under a $16 \mathrm{~h}$ light $/ 8 \mathrm{~h}$ dark cycle at $26 \pm 1{ }^{\circ} \mathrm{C}$ for two months. Leaf discs were dissected and submerged in the Agrobacterium mixture. The explants were cultured on a shoot-inducing medium containing $50 \mathrm{mg} \cdot \mathrm{L}^{-1}$ kanamycin to select transgenic calli. The regenerated shoots were subsequently transferred onto root-inducing MS medium to enable rooting prior to being transplanted into a greenhouse. The transgenic tobacco plants were grown to maturity under the same conditions as above and we obtained more than $20 \mathrm{~T}_{0}$ transgenic lines. Five or more $T_{1}$ transgenic lines were generated from each self-pollination of the $T_{0}$ lines. The flowers of three or more individuals in each $\mathrm{T}_{1}$ line showed decreases in pinkness to various extents compared to WT flowers. We classified the $\mathrm{T}_{1}$ lines into two groups (LP and PP) based on the observed changes in petal color and selected two representative plants from each group. Petals were collected from at least ten flowers of each representative plant and ground to a powder using liquid nitrogen for further analysis.

\subsection{HPLC Analysis of Flavonoids}

The accumulation of flavonoid aglycones in the petals was analyzed as described previously [57], with some modifications. Briefly, $100 \mathrm{mg}$ of ground petal sample was subjected to a 2-h acid hydrolysis in $300 \mu \mathrm{L}$ of $50 \%$ methanol containing $2 \mathrm{~N} \mathrm{HCl}$ at $90^{\circ} \mathrm{C}$. After centrifugation at $15,000 \times g$ for $10 \mathrm{~min}$ at $4{ }^{\circ} \mathrm{C}$, the supernatant was transferred to a new tube. The remaining pellet was rinsed with $200 \mu \mathrm{L}$ acid hydrolysis solution, which was then combined with the first extract. A $10 \mu \mathrm{L}$ aliquot of the extract was used in a HPLC analysis performed on an LC-20A HPLC system (Shimadzu, Kyoto, Japan) equipped with an Inertsil-ODS3 C18 column ( $5 \mu \mathrm{m}, 250 \times 4.6 \mathrm{~mm}$; GL Science, Eindhoven, Netherlands). The chromatographic separation was carried out using $0.1 \%$ formic acid in water (solution A) and $0.1 \%$ formic acid in acetonitrile (solution B) with the following gradient conditions; 0-30 min, linear gradient of $5-55 \%(v / v)$ solution B; 30-45 min, linear gradient of 55-65\% (v/v) solution B; and 45-50 min, linear gradient of $65-100 \%(v / v)$ solution $B$ at a flow rate of $1 \mathrm{~mL} \cdot \mathrm{min}^{-1}$. The temperature of the column was maintained at $40{ }^{\circ} \mathrm{C}$. A diode-array detector was used for compound detection. The spectra of the compounds were recorded between 210 and $800 \mathrm{~nm}$, and the peak corresponding to each compound was identified by comparing the retention times and UV spectra with those of the standards.

\subsection{Protein Extraction and Immunoblot Analysis}

Each ground petal sample was mixed with three volumes of pre-chilled protein extraction buffer containing $50 \mathrm{mM}$ Tris-Cl (pH 8.0), 2 mM EDTA, $250 \mathrm{mM}$ sucrose, $2 \mathrm{mM}$ DTT, and $200 \mu \mathrm{M}$ phenylmethylsulfonyl fluoride. The extracts were collected in $1.5 \mathrm{~mL}$ tubes and centrifuged at $6000 \times \mathrm{g}$ for $10 \mathrm{~min}$ at $4{ }^{\circ} \mathrm{C}$, after which the supernatants were transferred to new $1.5 \mathrm{~mL}$ tubes. This fraction was referred to as the total protein. The soluble and microsomal proteins were separated from the total protein using a previously described method [65], with some modifications. $\mathrm{NaCl}$ and PEG4000 were added to the total protein solution to concentrations of $150 \mathrm{mM}$ and $0.1 \mathrm{~g} \cdot \mathrm{mL}^{-1}$, respectively. After incubation on ice for $15 \mathrm{~min}$, the microsomal fractions were collected by centrifugation (10 min, $\left.10,000 \times g, 4^{\circ} \mathrm{C}\right)$. The supernatants were transferred to new $1.5 \mathrm{~mL}$ tubes, and were referred to as 
the soluble protein. The collected microsomal pellet was resuspended in TEG buffer (50 $\mathrm{mM}$ Tris (pH 7.5), 1 mM EDTA, and 30\% glycerol). Aliquots of the microsomal fractions were shock-frozen in liquid nitrogen and stored at $-80^{\circ} \mathrm{C}$ until further use. The protein concentrations were determined using the Bradford reagent (Bio-Rad Laboratories), and $12 \mu \mathrm{g}$ of each protein sample was subjected to immunoblot analysis with the anti-c-myc antibody, as previously described [65].

\subsection{RNA Extraction and $q P C R$ Analysis}

Total RNA was prepared from the petals of WT and transgenic tobacco flowers and the petals of mock- and flavonol-treated flowers using a FavorPrep ${ }^{\mathrm{TM}}$ Plant Total RNA Mini Kit (Favorgen, Pingtung, Taiwan), according to the manufacturer's instructions. The cDNAs were synthesized from $1.5 \mu \mathrm{g}$ total RNA using an amfiRivert cDNA Synthesis Platinum Master Mix (GenDEPOT, TX, USA). The qPCRs were performed using AccuPower 2x Greenstar qPCR Master Mix (Bioneer, Daejun, Republic of Korea) and the Bio-Rad CFX96 Detection System (Bio-Rad Laboratories, CA, USA), according to the manufacturer's instructions. The expression levels of the target genes were normalized against the expression of the tobacco glyceraldehyde 3-phosphate dehydrogenase gene (NtGAPDH). The gene-specific primers used for qPCR analysis are listed in Table 1.

\subsection{Tobacco Seedling Culture and Exogenous Rutin Treatment}

Seeds of wild-type and transgenic $\left(\mathrm{T}_{3}\right)$ tobacco were surface sterilized and grown on MS medium containing $0.4 \%$ plant agar without sucrose under a $16 \mathrm{~h}$ light $/ 8 \mathrm{~h}$ dark cycle at $26 \pm 1{ }^{\circ} \mathrm{C}$ for 8 days. Eight-day-old seedlings at the same growth stage were transferred to MS medium solidified with $0.8 \%$ gelrite in square dishes and grown vertically for eight more days. For exogenous rutin treatment, stock solutions were prepared by dissolving rutin in dimethyl sulfoxide (DMSO) at concentrations of $50 \mathrm{mM}$ and $10 \mathrm{mM}$, which were added to the MS medium at a ratio of $1 / 1000(v / v)$. For the mock treatment, only DMSO was added to the MS medium at the same ratio. Eight-day-old wild-type seedlings were transferred to these media and cultured vertically for eight more days. 16-day-old-seedlings were photographed on the dishes, and their root hairs were identified using a microscope. The primary root lengths of the 30 seedling were measured and averaged. We also measured the lengths of the longest root hair in the region up to $10 \mathrm{~mm}$ above the root tip in at least eight primary roots and then averaged.

\subsection{DPBA Staining}

The roots of 16-day-old seedlings were cut, submerged in an aqueous solution of $0.25 \%(w / v)$ DPBA (Sigma-Aldrich, Steinheim, Germany) and 0.2\% (v/v) Triton X-100, and incubated on a rotary shaker at $20 \mathrm{rpm}$ for $2 \mathrm{~h}$. The roots were washed three times with deionized water, and the fluorescence of flavonol-DPBA was visualized in vivo by confocal fluorescence microscopy (Leica TCS SP8; Leica Microsystems, Wetzlar, Germany). Fluorescence emission was captured at 475-504 nm for kaempferol and $577-619 \mathrm{~nm}$ for quercetin after excitation at 450-490 $\mathrm{nm}$ [66].

\subsection{Chemical Standards}

$( \pm)$-Naringenin, $( \pm)$-eriodictyol, $( \pm)$-DHK, $( \pm)$-DHQ, kaempferol, quercetin, and rutin hydrate were purchased from Sigma-Aldrich (St. Louis, USA), and cyanidin chloride and kaempferol-3-O-rutinoside were purchased from Extrasynthese (Extrasynthese, Genay Cedex, France). The flavanones, dihydroflavonols and flavonols were prepared as 100-mM stock solutions in DMSO, and cyanidin chloride was prepared to $100 \mathrm{mM}$ in $50 \%$ methanol containing $1.2 \mathrm{~N} \mathrm{HCl}$. An external UV standard calibration was carried out to obtain the calibration curves for kaempferol, quercetin, and cyanidin chloride, which were used as standards to quantify the flavonol aglycones and glucosides, and cyanidin aglycones and glucosides. 


\subsection{Statistical Analysis}

Data were expressed as the mean of three independent replicates. Statistical significance was evaluated by one-way ANOVA with post-hoc Tukey's tests using the SPSS Statistics program (version 25, IBM, NY, USA).

Author Contributions: Conceptualization, S.-H.L.; Data curation, S.P. and S.-H.L.; Investigation, S.P. and J.-Y.L.; Methodology, S.P., D.-H.K. and J.-H.Y.; Supervision, S.-H.L.; Writing—original draft, S.P.; Writing—review \& editing, S.-H.L. All authors have read and agreed to the published version of the manuscript.

Funding: This work was supported by funding from the National Academy of Agricultural Science (PJ014838) and a grant from the Next-Generation BioGreen 21 Program (PJ013360 and PJ013346), Rural Development Administration, Republic of Korea.

Conflicts of Interest: The authors declare no conflict of interest.

\section{References}

1. Winkel-Shirley, B. Biosynthesis of flavonoids and effects of stress. Curr. Opin. Plant Biol. 2002, 5, 218-223. [CrossRef]

2. Williams, C.A.; Grayer, R.J. Anthocyanins and other flavonoids. Nat. Prod. Rep. 2004, 21, 539-573. [CrossRef]

3. Ferrer, J.L.; Austin, M.B.; Stewart, C.; Noe, J.P. Structure and function of enzymes involved in the biosynthesis of phenylpropanoids. Plant Physiol. Biochem. 2008, 46, 356-370. [CrossRef]

4. Zhang, S.Z.; Yang, X.N.; Coburn, R.A.; Morris, M.E. Structure activity relationships and quantitative structure activity relationships for the flavonoid-mediated inhibition of breast cancer resistance protein. Biochem. Pharmacol. 2005, 70, 627-639. [CrossRef]

5. Jacobs, M.; Rubery, P.H. Naturally occurring auxin transport regulators. Science 1988, 241, 346-349. [CrossRef]

6. Hungria, M.; Joseph, C.M.; Phillips, D.A. Anthocyanidins and flavonols, major nod gene inducers from seeds of a black-seeded common bean (Phaseolus vulgaris L.). Plant Physiol. 1991, 97, 751-758. [CrossRef]

7. Mo, Y.; Nagel, C.; Taylor, L.P. Biochemical complementation of chalcone synthase mutants defines a role for flavonols in functional pollen. Proc. Natl. Acad. Sci. USA 1992, 89, 7213-7217. [CrossRef]

8. Vogt, T.; Wollenweber, E.; Taylor, L.P. The structural requirements of flavonols that induce pollen germination of conditionally male fertile Petunia. Phytochemistry 1995, 38, 589-592. [CrossRef]

9. Solovchenko, A.; Schmitz-Eiberger, M. Significance of skin flavonoids for UV-B-protection in apple fruits. J. Exp. Bot. 2003, 54, 1977-1984. [CrossRef]

10. Winkel-Shirley, B. Flavonoid biosynthesis. A colorful model for genetics, biochemistry, cell biology, and biotechnology. Plant Physiol. 2001, 126, 485-493. [CrossRef]

11. Hassan, S.; Mathesius, U. The role of flavonoids in root-rhizosphere signaling: Opportunities and challenges for improving plant-microbe interactions. J. Exp. Bot. 2012, 63, 3429-3444. [CrossRef]

12. Sparvoli, F.; Martin, C.; Scienza, A.; Gavazzi, G.; Tonelli, C. Cloning and molecular analysis of structural genes involved in flavonoid and stilbene biosynthesis in grape (Vitis vinifera L.). Plant Mol. Biol. 1994, 24, 743-755. [CrossRef]

13. Yu, B.; Zhang, D.; Huang, C.H.; Qian, M.J.; Zheng, X.Y.; Teng, Y.W.; Su, J.; Shu, Q. Isolation of anthocyanin biosynthetic genes in red Chinese sand pear (Pyrus pyrifolia Nakai) and their expression as affected by organ/tissue, cultivar, bagging and fruit side. Sci. Hort. 2012, 136, 29-37. [CrossRef]

14. Huang, J.; Gu, M.; Lai, Z.; Fan, B.; Shi, K.; Zhou, Y.H.; Yu, J.Q.; Chen, Z. Functional analysis of the arabidopsis $P A L$ gene family in plant growth, development, and response to environmental stress. Plant Physiol. 2010, 153, 1526-1538. [CrossRef]

15. Cos, P.; Calomme, M.; Sindambiwe, J.B.; Bruyne, T.D.; Cimanga, K.; Pieters, L.; Vlietinck, A.J.; Berghe, D.V. Cytotoxicity and lipid peroxidation-inhibiting activity of flavonoids. Planta Med. 2001, 67, 515-519. [CrossRef]

16. Bowles, D.; Lim, E.K.; Poppenberger, B.; Vaistij, F.E. Glycosyltransferases of lipophilic small molecules. Annu. Rev. Plant Biol. 2006, 57, 567-597. [CrossRef]

17. Winkel-Shirley, B. The biosynthesis of flavonoids. In The Science of Flavonoids; Grotewold, E., Ed.; Springer Science+Business Media, Inc.: New York, NY, USA, 2006; pp. 71-95. [CrossRef] 
18. Moreira, M.R.; Kanashiro, A.; Kabeya, L.M.; Polizello, A.C.; Azzolini, A.E.; Curti, C.; Oliveira, C.A.; T-do Amaral, A.; Lucisano-Valim, Y.M. Neutrophil effector functions triggered by Fc-gamma and/or complement receptors are dependent on B-ring hydroxylation pattern and physicochemical properties of flavonols. Life Sci. 2007, 81, 317-326. [CrossRef]

19. Xiao, J.; Cao, H.; Wang, Y.; Zhao, J.; Wei, X. Glycosylation of dietary flavonoids decreases the affinities for plasma protein. J. Agri. Food Chem. 2009, 57, 6642-6648. [CrossRef]

20. Nielsen, K.; Deroles, S.C.; Markham, K.R.; Bradley, M.J.; Podivinsky, E.; Manson, D. Antisense flavanol synthase alters co-pigmentation and flower color in lisianthus. Mol. Breeding 2002, 9, 615-622. [CrossRef]

21. Davies, K.M.; Schwinn, K.E.; Deroles, S.C.; Manson, D.G.; Lewis, D.H.; Bloor, S.J.; Bradley, J.M. Enhancing anthocyanin production by altering competition for substrate between flavonol synthase and dihydroflavonol 4-reductase. Euphytica 2003, 131, 259-268. [CrossRef]

22. Yuan, Y.W.; Rebocho, A.B.; Sagawa, J.M.; Stanley, L.E.; Bradshaw, H.D. Competition between anthocyanin and flavonol biosynthesis produces spatial pattern variation of floral pigments between Mimulus species. Proc. Natl. Acad. Sci. USA. 2016, 113, 2448-2453. [CrossRef]

23. Lim, S.H.; You, M.K.; Kim, D.H.; Kim, J.K.; Lee, J.Y.; Ha, S.H. RNAi-mediated suppression of dihydroflavonol 4-reductase in tobacco allows fine-tuning of flower color and flux through the flavonoid biosynthetic pathway. Plant Physiol. Biochem. 2016, 109, 482-490. [CrossRef]

24. Luo, P.; Ning, G.; Wang, Z.; Shen, Y.; Jin, H.; Li, P.; Huang, S.; Zhao, J.; Bao, M. Disequilibrium of flavonol synthase and dihydroflavonol-4-reductase expression associated tightly to white vs. red color flower formation in plants. Front. Plant Sci. 2016, 6, 1257. [CrossRef]

25. Borevitz, J.O.; Xia, Y.; Blount, J.; Dixon, R.A.; Lamb, C. Activation tagging identifies a conserved MYB regulator of phenylpropanoid biosynthesis. Plant Cell 2000, 12, 2383-2394. [CrossRef]

26. Zimmermann, I.M.; Heim, M.A.; Weisshaar, B.; Uhrig, J.F. Comprehensive identification of Arabidopsis thaliana MYB transcription factors interacting with R/B-like BHLH proteins. Plant J. 2004, 40, 22-34. [CrossRef]

27. Ramsay, N.A.; Glover, B.J. MYB-bHLH-WD40 protein complex and the evolution of cellular diversity. Trends Plant Sci. 2005, 10, 63-70. [CrossRef]

28. Stracke, R.; Ishihara, H.; Huep, G.; Barsch, A.; Mehrtens, F.; Niehaus, K.; Weisshaar, B. Differential regulation of closely related R2R3-MYB transcription factors controls flavonol accumulation in different parts of the Arabidopsis thaliana seedling. Plant J. 2007, 50, 660-677. [CrossRef]

29. Luo, J.; Butelli, E.; Hill, L.; Parr, A.; Niggeweg, R.; Bailey, P.; Weisshaar, B.; Martin, C. AtMYB12 regulates caffeoyl quinic acid and flavonol synthesis in tomato: Expression in fruit results in very high levels of both types of polyphenol. Plant J. 2008, 56, 316-326. [CrossRef]

30. Falcone Ferreyra, M.L.; Rius, S.; Emiliani, J.; Pourcel, L.; Feller, A.; Morohashi, K.; Casati, P.; Grotewold, E. Cloning and characterization of a UV-B-inducible maize flavonol synthase. Plant J. 2010, 62, 77-91. [CrossRef]

31. Jiang, R.; Tian, J.; Song, T.; Zhang, J.; Yao, Y. The Malus crabapple transcription factor McMYB10 regulates anthocyanin biosynthesis during petal coloration. Sci. Hort. 2014, 166, 42-49. [CrossRef]

32. Lee, S.H.; Cho, H.T. PINOID positively regulates auxin efflux in arabidopsis root hair cells and tobacco cells. Plant Cell 2006, 18, 1604-1616. [CrossRef] [PubMed]

33. Kuhn, B.M.; Nodzyński, T.; Errafi, S.; Bucher, R.; Gupta, S.; Aryal, B.; Dobrev, P.; Bigler, L.; Geisler, M.; Zažímalová, E.; et al. Flavonol-induced changes in PIN2 polarity and auxin transport in the Arabidopsis thaliana rol1-2 mutant require phosphatase activity. Sci. Rep. 2017, 7, 41906. [CrossRef]

34. Tsukagoshi, H.; Busch, W.; Benfey, P.N. Transcriptional regulation of ROS controls transition from proliferation to differentiation in the root. Cell 2010, 143, 606-616. [CrossRef] [PubMed]

35. Silva-Navas, J.; Moreno-Risueno, M.A.; Manzano, C.; Téllez-Robledo, B.; Navarro-Neila, S.; Carrasco, V.; Pollmann, S.; Gallego, F.J.; Del Pozo, J.C. Flavonols mediate root phototropism and growth through regulation of proliferation-to-differentiation transition. Plant Cell 2016, 28, 1372-1387. [CrossRef] [PubMed]

36. Tan, H.; Man, C.; Xie, Y.; Yan, J.; Chu, J.; Huang, J. A crucial role of GA-regulated flavonol biosynthesis in root growth of Arabidopsis. Mol. Plant 2019, 12, 521-537. [CrossRef] [PubMed]

37. Maloney, G.S.; DiNapoli, K.T.; Muday, G.K. The anthocyanin reduced tomato mutant demonstrates the role of flavonols in tomato lateral root and root hair development. Plant Physiol. 2014, 166, 614-631. [CrossRef] [PubMed] 
38. Ringli, C.; Bigler, L.; Kuhn, B.M.; Leiber, R.M.; Diet, A.; Santelia, D.; Frey, B.; Pollmann, S.; Klein, M. The modified flavonol glycosylation profile in the Arabidopsis rol1 mutants results in alterations in plant growth and cell shape formation. Plant Cell 2008, 20, 1470-1481. [CrossRef]

39. Yin, R.; Han, K.; Heller, W.; Albert, A.; Dobrev, P.I.; Zažímalová, E.; Schäffner, A.R. Kaempferol 3-O-rhamnoside-7-O-rhamnoside is an endogenous flavonol inhibitor of polar auxin transport in Arabidopsis shoots. New Phytol. 2014, 201, 466-475. [CrossRef]

40. Grunewald, W.; De Smet, I.; Lewis, D.R.; Löfke, C.; Jansen, L.; Goeminne, G.; Vanden Bossche, R.; Karimi, M.; De Rybel, B.; Vanholme, B.; et al. Transcription factor WRKY23 assists auxin distribution patterns during Arabidopsis root development through local control on flavonol biosynthesis. Proc. Natl. Acad. Sci. USA. 2012, 31, 109. [CrossRef]

41. Zhang, Y.; De Stefano, R.; Robine, M.; Butelli, E.; Bulling, K.; Hill, L.; Rejzek, M.; Martin, C.; Schoonbeek, H.J. Different reactive oxygen species scavenging properties of flavonoids determine their abilities to extend the shelf life of tomato. Plant Physiol. 2015, 169, 1568-1583. [CrossRef]

42. Pelletier, M.K.; Murrell, J.R.; Shirley, B.W. Characterization of flavonol synthase and leucoanthocyanidin dioxygenase genes in Arabidopsis. Further evidence for differential regulation of "early" and "late" genes. Plant Physiol. 1997, 113, 1437-1445. [CrossRef] [PubMed]

43. Lin, G.Z.; Lian, Y.J.; Ryu, J.H.; Sung, M.K.; Park, J.S.; Park, H.J.; Park, B.K.; Shin, J.S.; Lee, M.S.; Cheon, C.I. Expression and purification of His-tagged flavonol synthase of Camellia sinensis from Escherichia coli. Protein Expr. Purif. 2007, 55, 287-292. [CrossRef] [PubMed]

44. Wellmann, F.; Lukacin, R.; Moriguchi, T.; Britsch, L.; Schiltz, E.; Matern, U. Functional expression and mutational analysis of flavonol synthase from Citrus unshiu. Eur. J. Biochem. 2002, 269, 4134-4142. [CrossRef]

45. Li, C.; Bai, Y.; Li, S.; Chen, H.; Han, X.; Zhao, H.; Shao, J.; Park, S.U.; Wu, Q. Cloning, characterization, and activity analysis of a flavonol synthase gene FtFLS1 and its association with flavonoid content in tartary buckwheat. J. Agric. Food Chem. 2012, 60, 5161-5168. [CrossRef]

46. Xu, F.; Li, L.; Zhang, W.; Cheng, H.; Sun, N.; Cheng, S.; Wang, Y. Isolation, characterization, and function analysis of a flavonol synthase gene from Ginkgo biloba. Mol. Biol. Rep. 2012, 39, 2285-2296. [CrossRef] [PubMed]

47. Holton, T.A.; Brugliera, F.; Tanaka, Y. Cloning and expression of flavonol synthase from Petunia hybrida. Plant J. 1993, 4, 1003-1010. [CrossRef] [PubMed]

48. Fujita, A.; Goto-Yamamoto, N.; Aramaki, I.; Hashizume, K. Organ-specific transcription of putative flavonol synthase genes of grapevine and effects of plant hormones and shading on flavonol biosynthesis in grape berry skins. Biosci. Biotechnol. Biochem. 2006, 70, 632-638. [CrossRef]

49. Park, S.; Kim, D.H.; Lee, J.Y.; Ha, S.H.; Lim, S.H. Comparative analysis of two flavonol synthases from different-colored onions provides insight into flavonoid biosynthesis. J. Agric. Food Chem. 2017, 65, 5287-5298. [CrossRef]

50. Park, S.; Kim, D.H.; Park, B.R.; Lee, J.Y.; Lim, S.H. Molecular and Functional Characterization of Oryza sativa Flavonol Synthase (OsFLS), a Bifunctional Dioxygenase. J. Agric. Food Chem. 2019, 67, 7399-7409. [CrossRef]

51. Owens, D.K.; Crosby, K.C.; Runac, J.; Howard, B.A.; Winkel, B.S. Biochemical and genetic characterization of Arabidopsis flavanone 3beta-hydroxylase. Plant Physiol. Biochem. 2008, 46, 833-843. [CrossRef]

52. Peer, W.A.; Brown, D.E.; Tague, B.W.; Muday, G.K.; Taiz, L.; Murphy, A.S. Flavonoid accumulation patterns of transparent testa mutants of Arabidopsis. Plant Physiol. 2001, 126, 536-548. [CrossRef] [PubMed]

53. Wang, B.; Zhao, Q. Membrane-bound metabolons. Nat. Plants. 2018, 4, 245-246. [CrossRef] [PubMed]

54. Winkel, B.S.J. Metabolic channeling in plants. Annu. Rev. Plant Biol. 2004, 55, 85-107. [CrossRef] [PubMed]

55. Vu, T.T.; Jeong, C.Y.; Nguyen, H.N.; Lee, D.; Lee, S.A.; Kim, J.H.; Hong, S.W.; Lee, H. Characterization of Brassica napus flavonol synthase involved in flavonol biosynthesis in Brassica napus L. J. Agric. Food Chem. 2015, 63, 7819-7829. [CrossRef] [PubMed]

56. Nakatsuka, T.; Abe, Y.; Kakizaki, Y.; Yamamura, S.; Nishihara, M. Production of red-flowered plants by genetic engineering of multiple flavonoid biosynthetic genes. Plant Cell Rep. 2007, 26, 1951-1959. [CrossRef]

57. Kim, D.H.; Park, S.; Lee, J.Y.; Ha, S.H.; Lim, S.H. Enhancing flower color through simultaneous expression of the B-peru and $m P A P 1$ transcription factors under control of a flower-specific promoter. Int. J. Mol. Sci. 2018, 19, 309. [CrossRef] [PubMed]

58. Mahajan, M.; Ahuja, P.S.; Yadav, S.K. Post-transcriptional silencing of flavonol synthase mRNA in tobacco leads to fruits with arrested seed set. PLOS ONE 2011, 6, e28315. [CrossRef] 
59. Chen, S.; Wu, F.; Li, Y.; Qian, Y.; Pan, X.; Li, F.; Wang, Y.; Wu, Z.; Fu, C.; Lin, H.; et al. NtMYB4 and NtCHS1 are critical factors in the regulation of flavonoid biosynthesis and are involved in salinity responsiveness. Front. Plant Sci. 2019, 10, 178. [CrossRef]

60. Brown, D.E.; Rashotte, A.M.; Murphy, A.S.; Normanly, J.; Tague, B.W.; Peer, W.A.; Taiz, L.; Muday, G.K. Flavonoids act as negative regulators of auxin transport in vivo in arabidopsis. Plant Physiol. 2001, 126, 524-535. [CrossRef]

61. Peer, W.A.; Bandyopadhyay, A.; Blakeslee, J.J.; Makam, S.N.; Chen, R.J.; Masson, P.H.; Murphy, A.S. Variation in expression and protein localization of the PIN family of auxin efflux facilitator proteins in flavonoid mutants with altered auxin transport in Arabidopsis thaliana. Plant Cell 2004, 16, 1898-1911. [CrossRef]

62. Foreman, J.; Demidchik, V.; Bothwell, J.H.; Mylona, P.; Miedema, H.; Torres, M.A.; Linstead, P.; Costa, S.; Brownlee, C.; Jones, J.D.; et al. Reactive oxygen species produced by NADPH oxidase regulate plant cell growth. Nature 2003, 422, 442-446. [CrossRef] [PubMed]

63. Dubin, M.J.; Bowler, C.; Benvenuto, G. A modified Gateway cloning strategy for overexpressing tagged proteins in plants. Plant Methods 2008, 22, 4:3. [CrossRef]

64. Karimi, M.; Inzé, D.; Depicker, A. GATEWAYTM vectors for Agrobacterium-mediated plant transformation. Trends Plant Sci. 2002, 7, 193-195. [CrossRef]

65. Park, S.; Choi, M.J.; Lee, J.Y.; Kim, J.K.; Ha, S.H.; Lim, S.H. Molecular and Biochemical Analysis of Two Rice flavonoid 3'-hydroxylase to evaluate their roles in flavonoid biosynthesis in rice grain. Int. J. Mol. Sci. 2016, 17, 1549. [CrossRef]

66. Santelia, D.; Henrichs, S.; Vincenzetti, V.; Sauer, M.; Bigler, L.; Klein, M.; Bailly, A.; Lee, Y.; Friml, J.; Geisler, M.; et al. Flavonoids redirect PIN-mediated polar auxin fluxes during root gravitropic responses. J. Biol. Chem. 2008, 283, 31218-31226. [CrossRef] [PubMed]

(C) 2020 by the authors. Licensee MDPI, Basel, Switzerland. This article is an open access article distributed under the terms and conditions of the Creative Commons Attribution (CC BY) license (http://creativecommons.org/licenses/by/4.0/). 